\title{
Invasion of ovarian cancer cells is induced byPITX2-mediated activation of TGF- $\beta$ and Activin-A
}

Moitri Basu', Rahul Bhattacharya', Upasana Ray ${ }^{1}$, Satinath Mukhopadhyay ${ }^{2}$, Uttara Chatterjee ${ }^{3}$ and Sib Sankar Roy ${ }^{1 *}$

\begin{abstract}
Background: Most ovarian cancers are highly invasive in nature and the high burden of metastatic disease make them a leading cause of mortality among all gynaecological malignancies. The homeodomain transcription factor, PITX2 is associated with cancer in different tissues. Our previous studies demonstrated increased PITX2 expression in human ovarian tumours. Growing evidence linking activation of TGF- $\beta$ pathway by homeodomain proteins prompted us to look for the possible involvement of this signalling pathway in PITX2-mediated progression of ovarian cancer.
\end{abstract}

Methods: The status of TGF- $\beta$ signalling in human ovarian tissues was assessed by immunohistochemistry. The expression level of TGFB/INHBA and other invasion-associated genes was measured by quantitative-PCR (Q-PCR) and Western Blot after transfection/treatments with clones/reagents in normal/cancer cells. The physiological effect of PITX2 on invasion/motility was checked by matrigel invasion and wound healing assay. The PITX2- and activin-induced epithelial-mesenchymal transition (EMT) was evaluated by Q-PCR of respective markers and confocal/phase-contrast imaging of cells.

Results: Human ovarian tumours showed enhanced TGF- $\beta$ signalling. Our study uncovers the PITX2-induced expression of TGFB1/2/3 as well as INHBA genes $(p<0.01)$ followed by SMAD2/3-dependent TGF- $\beta$ signalling pathway. PITX2-induced TGF- $\beta$ pathway regulated the expression of invasion-associated genes, SNA/1, CDH1 and MMP9 $(p<0.01)$ that accounted for enhanced motility/invasion of ovarian cancers. Snail and MMP9 acted as important mediators of PITX2-induced invasiveness of ovarian cancer cells. PITX2 over-expression resulted in loss of epithelial markers $(p<0.01)$ and gain of mesenchymal markers $(p<0.01)$ that contributed significantly to ovarian oncogenesis. PITX2-induced INHBA expression $(p<0.01)$ contributed to EMT in both normal and ovarian cancer cells.

Conclusions: Overall, our findings suggest a significant contributory role of PITX2 in promoting invasive behaviour of ovarian cancer cells through up-regulation of TGFB/INHBA. We have also identified the previously unknown involvement of activin-A in promoting EMT. Our work provides novel mechanistic insights into the invasive behavior of ovarian cancer cells. The extension of this study have the potential for therapeutic applications in future.

Keywords: PITX2, TGF- $\beta$ signalling, Activin-A, Invasion, EMT, IOSE, Ovarian cancer cells

\footnotetext{
* Correspondence: sibsankar@iicb.res.in

${ }^{1}$ Cell Biology and Physiology Division, CSIR-Indian Institute of Chemical Biology, Council of Scientific and Industrial Research, 4 Raja S. C. Mullick Road, Kolkata 700032, India

Full list of author information is available at the end of the article
} 


\section{Background}

Ovarian cancer is a highly metastatic disease and is the leading cause of death among all gynaecological malignancies [1]. Unfortunately, the disease is often detected at an advanced stage (stages III-IV) and progresses very rapidly, as it acquires an aggressive phenotype. A number of growth factors, including transforming growth factor- $\beta$ (TGF- $\beta$ ) regulate the proliferation of ovarian surface epithelial (OSE) cells and increases metastasis [2]. TGF- $\beta$ binds to its specific receptors, type-I (TRRI) and type-II (TRRII). Upon ligand binding, T $\beta$ RII trans-phosphorylates and activates T $\beta R I$, which in turn phosphorylates Smad2 and Smad3 $[3,4]$. The latter two then bind to Smad4 and the complex translocates to the nucleus to regulate the expression of target genes. Other member of the TGF- $\beta$ superfamily, like activin transduces signals mainly through the SMAD2/3-dependent pathway [5]. INHBA forms a disulfide-linked homodimer, known as activinA which is a polypeptide hormone of primarily gonadal origin $[6,7]$. The mojor gonadal sites of its production is Sertoli cells of males and ovarian granulosa cells of female origin [6, 7]. High levels of activin- $\beta_{\mathrm{A}}$ subunit is detected in majority of the patients with granulosa cell tumors [8], but almost absent in ovarian epithelial tumors except mucinous carcinoma [9]. In addition, increased expression of activin-A is observed in esophageal [10] and colorectal carcinomas [11]. High expression of activin-A was found in stage IV colorectal cancer [12] and correlated with poor overall survival rate $[11,12]$. However, there are no reports on the regulation of activin-A and its role in epithelial ovarian cancer progression.

Highly invasive and metastatic behavior underpin the aggressive nature of ovarian cancers. Epithelial-mesenchymal transition (EMT) is a major mechanism for the conversion of early-stage tumors to invasive malignancies due to the loss of epithelial adherence and tight junctions [13, 14]. Transcription factor like Snail acts as a key regulator in the induction of cellular invasion, in part, by suppressing the expression of the epithelial specific adhesion molecule, Ecadherin and by increasing the expression of matrix metalloproteinases MMPs; [15]. TGF- $\beta$-signalling, on the other hand, enhances the invasive properties of ovarian cancers partially through up-regulation of MMPs [16].

The homeobox genes are widely implicated in various human cancers, acting as oncogenes or tumour suppressors [17-21]. Pituitary homeobox 2 (PITX2), a member of the bicoid/paired-like homeobox gene family, is a multifunctional transcription factor [22-24]. Three different isoforms of PITX2 (PITX2A/B/C), differ only in their amino terminus and regulate the transcription of target genes differentially [25]. Recently, several reports highlighted the association of PITX2 with progression of breast and colorectal cancers [26, 27]. We observed the up-regulated expression of PITX2 in ovarian tumours
[28] and simultaneously we found induced TGF- $\beta$ signaling pathway in the same tissue sections. Considering the importance of TGF- $\beta$ signalling pathway in promoting oncogenesis of several tissues, we aimed to investigate possible involvement of PITX2 in promoting invasiveness of ovarian cancer cells through the regulation of TGF- $\beta$ signalling pathways. We also explored the role of activin- $\mathrm{A}$ in the progression of epithelial ovarian cancers.

\section{Results}

Activation of TGF- $\beta$ signalling pathway in human ovarian tumours

We evaluated the status of TGF- $\beta$ signalling in ovarian tumours. The level of phospho-SMAD2, (as readout of active TGF signalling; Fig. 1a) was measured by immunohistochemical analysis. Confocal imaging of tissue sections showed intense staining of p-SMAD2 in human ovarian cancer (ii) compared to normal (i) tissues, supporting the activation of TGF- $\beta$ signalling pathway. The specificity of the staining was checked by staining the sections in presence of secondary antibody only and DAPI without primary antibody (Fig. 1b). Simultaneously, the increased expression of PITX2 was observed in the same ovarian tumor sections (i) compared to normal (ii) (Additional file 1: Figure S1).

\section{SMAD-dependent TGF- $\beta$ signalling is activated by PITX2 in ovarian cancer cells}

Considering the association of homeodomain proteins in activating TGF- $\beta$ signalling in different cancer types, we attempted to investigate whether PITX2 could activate the same in ovarian cancer cells. For that, the increased expression of PITX2 was verified by Western blot with lysate of PITX2A-transfected OAW-42 cells (Fig. 2a). The ectopic over-expression of $P I T X 2 A / B / C$ significantly enhanced the mRNA levels of $T G F-B 1 / B 2 / B 3$ in OAW-42 $(p<0.01$; Fig. 2 b) cells as shown by Q-PCR assay. Similarly, increase in TGF-B2/B3 was observed in SKOV-3 $(p<0.01$; Fig. $2 c)$ cells upon over-expression of PITX2 isoforms. The incubation of freshly cultured cells with the conditioned medium of PITX2A-transfected cells (PITX2-CM) induced the p-SMAD2 level. This induction was reduced in presence of TGF- $\beta$ receptor inhibitor (TGFRI), suggesting the involvement of PITX2-mediated activation of TGF- $\beta$ signalling pathway both in SKOV-3 (Fig. 2d) and OAW-42 cells (Fig. 2e). Here, the treatment of cells with rhTGF $\beta-1$ also activated the p-SMAD2 level as a mark of positive control (Fig. 2d-e). The nuclear pSMAD2 level was enhanced by the treatment of SKOV-3 cells with PITX2-CM as observed by confocal imaging using specific antibody (Fig. 2f). In contrast, treatment with rhTGF $\beta 1$ in PITX2-siRNA transfected cells reduced the intensity of expression. Here, the reduction in PITX2 protein was confirmed by Western 


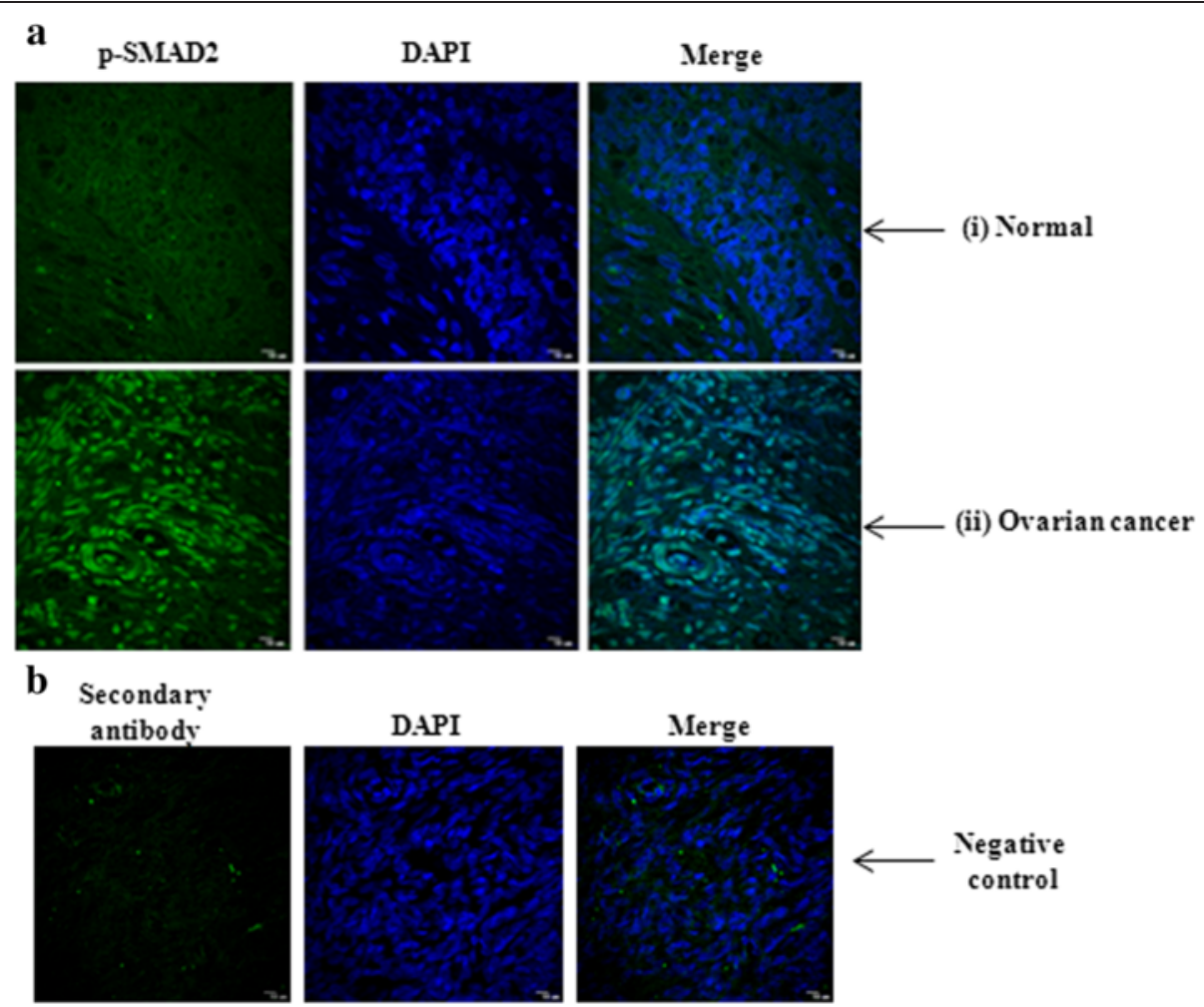

Fig. 1 The expression of p-SMAD2 is up-regulated in human ovarian cancer. a The level of p-SMAD2 was shown by IHC in human ovarian tissue-sections with p-SMAD2 antibody followed by Alexa Fluor-488 (green) of normal (i; $n=20$ ) and ovarian tumor (ii; $n=20$ ), out of which 15 samples are of high grade and 5 samples are benign. The DAPI-stained nuclei and the merged images were also shown. $\mathbf{b}$ The negative control images represent the staining in presence of secondary antibody and DAPI but without primary antibody. The images were taken at the same exposure time. Scale bar, $10 \mu \mathrm{m}$

blot with PITX2-siRNA trasfected cell lysate (Fig. 2g). Further, the ectopic over-expression of PITX2A/B/C augmented the activity of TGF $\beta / S M A D$-responsive reporter construct (p3TP-lux) by 3-5 folds (Fig. 2h) in OAW-42 cells, however, TGFRI-treatment suppressed this transactivation (Fig. 2h). Taken together, the results suggest activation of TGF- $\beta$ signalling pathway by PITX2.

\section{PITX2 contributes to the EMT and invasion of ovarian cancer cells}

In conjunction with our earlier finding of the upregulated expression of PITX2 in human ovarian tumors [20], we attempted to check the regulation of invasionassociated genes by PITX2. The transient transfection of PITX2 isoforms significantly increased the expression of these genes like Snail (SNAI1), Slug (SNAI2) and MMP9 in both SKOV-3 (Fig. 3a) and OAW-42 cells (Fig. 3b). In contrast, PITX2 over-expression reduced the mRNA level of E-cadherin (Fig. 3a-ii) in OAW-42 cells. Since EMT is an essential prerequisite for the metastasis of ovarian cancer, we tried to elucidate the role of PITX2 over-expression in inducing EMT. PITX2 isoforms significantly reduced $(p<0.01$; Fig. $2 \mathrm{c}-\mathrm{i})$ the expression of epithelial marker genes claudin-4 (CLD4), claudin-7 (CLD7) and desmoplakin (DSM), whereas the mesenchymal gene, vimentin (VIM; Fig. 3c-ii) was induced by all isoforms of PITX2 in SKOV-3 cells. Similarly, the expression of CLD4, CLD7 and DSM (Fig. 3d-i; $p<0.05$ ) were reduced while that of VIM (Fig. 3d-ii; $p<0.005$ ) was up-regulated in PITX2-overexpressed OAW-42 cells. Consistently, the expression of $\alpha$-smooth muscle actin ( $\alpha$-SMA, a mesenchymal marker) was more intense in PITX2-transfected SKOV-3 (Fig. 3e) and OAW-42 (Fig. 3f) cells as shown by Western-immunobloting. However, the protein level of claudin-7 was remarkably reduced in PITX2 over-expressed SKOV-3 (Fig. 3e) and OAW-42 (Fig. 3f) cells. The EMT-like phenotypical changes in IOSE cells were verified by bright field microscopy (Fig. 3g-i) and the actin rearrangement was observed by phalloidin staining (Fig. 3h-i). SKOV-3 cells also showed phenotypic changes upon PITX2Aoverexpression in phase contrast microscopy (Fig. 3g-ii). A significant decrease in E-cadherin was observed by immunostaining in PITX2A-transfected cells compared to controls (Fig. 3h-ii). There was a significant decrease $(p<0.01$; Fig. 3i) of the epithelial markers CLDN1 and CLDN7, while 


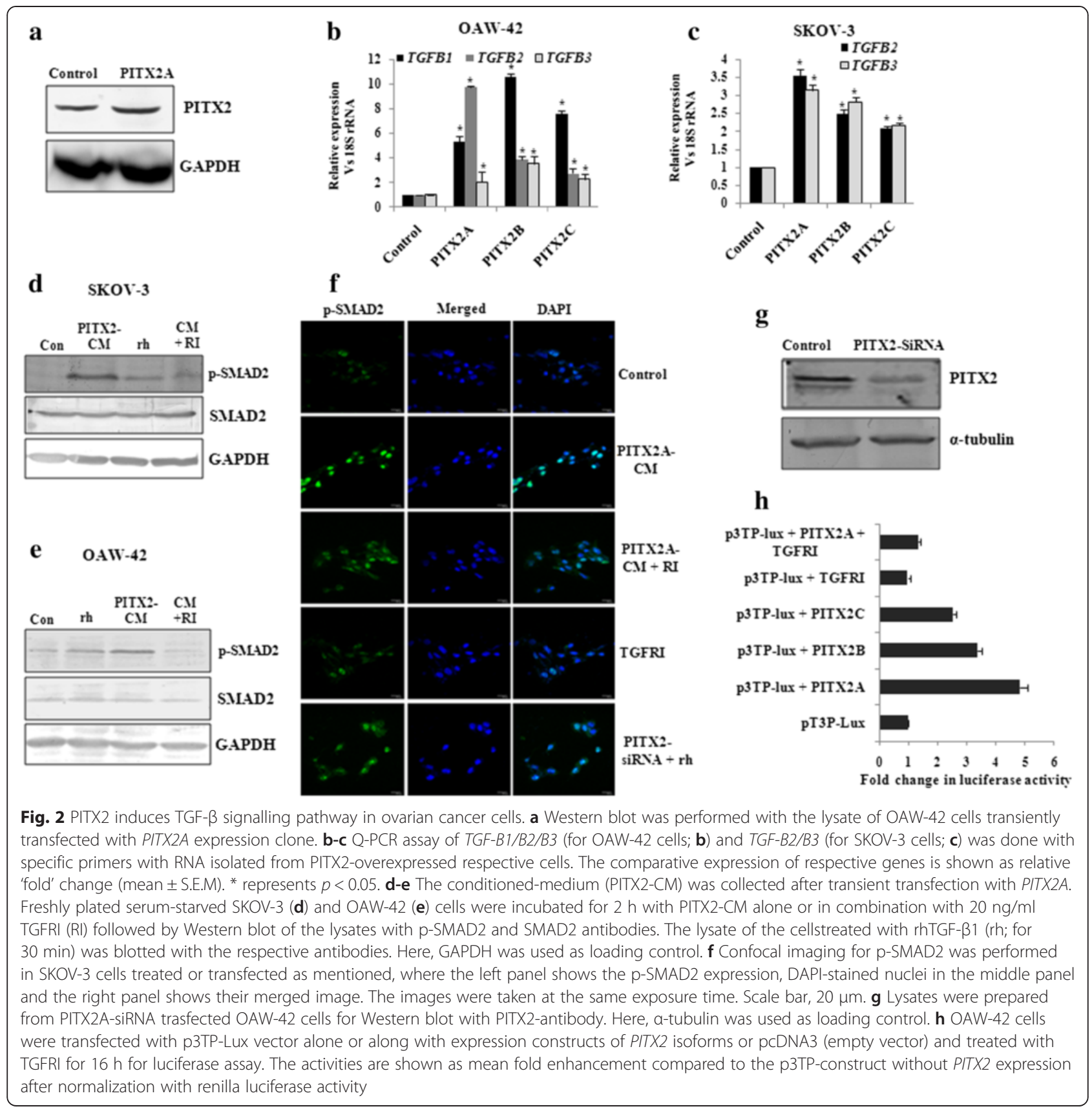

mesenchymal markers like $\mathrm{N}$-cadherin $(\mathrm{CDH} 2)$ and VIM showed 4.5-5.5 fold up-regulation (Fig. 3j) in IOSE cells transfected with PITX2A. Similar changes in parameters primarily observed during EMT were also noticed in PITX2 over-expressed cells.

\section{Migration and invasion of ovarian cancer cells are} enhanced by PITX 2 through TGF- $\beta$ pathway

To address the physiological significance of PITX2mediated regulation of TGF- $\beta$ pathway in promoting migration and invasion, wound healing assay was performed with SKOV-3 (Fig. 4a) and OAW-42 (Fig. 4b) cells. Treatment with rhTGF- $\beta 1$ (ii) for $24 \mathrm{~h}$ or transient transfection of PITX2A (iii) for the same duration exhibited faster wound closure than the control set (i). Treatment of transiently transfected cells with rhTGF- $\beta 1$ (iv) showed almost complete healing within the same period. Conversely, TGFRI-treatment (v) inhibited the healing, while ectopic over-expression of PITX2A slightly reduced its inhibitory effect (vi). The gap created by the wound before and after treatment/transfection has been depicted herewith. Matrigel invasion assay demonstrated $\sim 2.5$ folds increase ( $p<0.005$; Fig. $4 \mathrm{c}$ and e) in invasion of SKOV-3 cells upon transient transfection of 
PITX2A; the invasiveness was sharply reduced upon TGFRI treatment. In parallel, treatment of PITX2Atransfected cells with the rhTGF- $\beta 1$ increased the invasion by $\sim 3.5$ folds $(p<0.01$; Fig. $4 \mathrm{c}$ and e). The abovementioned effects were observed on OAW-42 cells (Fig. 4d and $\mathrm{f}$ ) as well.

Further, the involvement of TGF- $\beta$ signalling pathway on PITX2-mediated invasion and migration was verified by monitoring the expression of relevant genes . The expression of the SNAI1 was increased $\sim 7$ folds $(p<0.05)$ in PITX2A-overexpressed SKOV-3 cells, which was reduced to $<2$ folds $(p<0.01$; Fig. $4 \mathrm{~g})$ by TGFRI. The $\operatorname{rhTGF} \beta-1$ alone induced the mRNA of SNAI1 by $\sim 4$ folds $(p<0.01$; Fig. 4g). In contrast, PITX2A-suppressed expression of $C D H 1$ was rescued by TGFRI-treatment by $>60 \%$ ( $p<0.05$; Fig. 4h). Similarly, the MMP9 expression was shown to be induced by $\sim 16$ folds $(p<0.01$; Fig. $4 \mathrm{i})$ by PITX2A-transfection. However, the TGFRI severely reduced it to $\sim 8$ folds $(p<0.05$; Fig. $4 \mathrm{i})$. In agreement to QPCR result, the Western-blot with specific antibodies supported the regulation at the protein level by TGF- $\beta$ signalling pathway as well (Fig. 4j). To determine whether Snail and MMP9 contribute to PITX2-stimulated invasion, SKOV-3 cells were transfected with their respective siRNAs alone or along with PITX2A-expression vector followed by matrigel invasion assay. PITX2A induced the invasion of cells by $>2.5$ folds (Fig. 3c), which was reduced by $\sim 60 \%$ $(p<0.01$; Fig. $4 \mathrm{k})$ by either SNAI1-or MMP9-siRNA transfection into PITX2A-overexpressed cells.

\section{PITX2-mediated up-regulation of Activin-A leads to increased $p$-SMAD2 levels}

As p-SMAD2 level was higher in PITX2-CM treated cells than that of rhTGF- $\beta 1$ (Fig. 2c), we checked for other PITX2-regulated ligands for possible explanation. Since several PITX2-specific cis-elements are present in the promoter of INHBA (Fig. 5a), we verified PITX2mediated trans-activation of the same. ChIP assay with PITX2 antibody followed by PCR showed amplifications of the INHBA (Fig. $5 \mathrm{~b}$ ) promoter, indicating the binding of PITX2 with the respective promoter. The primers of an unrelated gene (GAPDH promoter) did not show any PCR amplification from the PITX2-IP DNA (Fig. 5c). All PCR products were sequenced to confirm their identities. Next, the promoter region of INHBA (Fig. 5a) was cloned into pGL3-basic vector. Transfection of OAW-42 cells with this reporter clone along with PITX2 expression constructs revealed activation of the promoter by $\sim 20-25$ folds (Fig. 5 b) compared to transfection with the reporter construct alone. Q-PCR demonstrated significant up-regulation of the mRNA level of INHBA (Fig. 5e) upon ectopic over-expression of PITX2 isoforms. To find out the physiological effect of Activin-A, the homodimer form of INHBA, serum-starved OAW-
42 cells were treated with recombinant protein. Westerm immunoblotting confirmed the induction of $\mathrm{p}$ SMAD2 level in the cell lysates (Fig. 5f), indicating activation of TGF- $\beta$ signalling pathway. Induction of $\mathrm{p}-$ SMAD2 was higher in cell lysates treated with $100 \mathrm{ng} / \mathrm{ml}$ of rhActivin-A compared to that treated with $10 \mathrm{ng} / \mathrm{ml} \mathrm{con-}$ centration. Therefore, the following experiments were done with $100 \mathrm{ng} / \mathrm{ml}$ rhActivin. Activin-A appeared to contribute directly to PITX2-induced p-SMAD2 level, as use of neutralizing antibody to Activin-A reduced the PITX2-CMenhanced p-SMAD2 (Fig. 5g).

\section{Activin-A induces EMT and invasion in both normal and ovarian cancer cells}

The trans-activation of INHBA gene by PITX2 (Fig. 5) made us curious whether it affects cellular invasiveness. Next, the treatment of IOSE and OAW-42 cells with rhActivin-A, the homodimer form of INHBA, resulted in the morphological changes (as checked by bright field microscopy; Fig. 6a i-ii) and actin rearrangements (through phalloidin staining followed by confocal microscopy; Fig. 6b i-ii) resembling that of mesenchymal cell type. For detailed study, we assessed the effect of activin-A on the expression of genes associated with cellular invasion and EMT. The expression of the EMT markers, including $C D H 1, C L D N 7$ was decreased by 60-70 \% (Fig. 6c; $p<0.05$ ) whereas the levels $C D H 2$ and VIM were increased by $\sim 2$ and 2.5 folds respectively (Fig. 6d) in IOSE cells. In addition, the expression of transcription factors including SNAI1, SNAI2, ZEB1, $Z E B 2$ was increased by $\sim 2-3$ folds (Fig. 6e, $p<0.01$ ), while $M M P 9$ expression was found $\sim 5$ folds increase (Fig. 6f) by treatment of OAW-42 cells with rhActivin-A. In addition, reduction in CLDN1 and CLDN7 and increase in VIM was observed by activin-A treatment (Fig. 6g). The change in the protein levels of VIM and E-cadherin by rhActivin-A (Fig. 6h) was consistent with Q-PCR data of the same in IOSE. Thus, overall findings clearly indicate the involvement of activin in promoting EMT.

\section{Activin-A contributes to PITX2-induced cellular invasion}

We next attempted to investigate the possible contribution of activin-A in PITX2-induced invasion and EMT in ovarian cancer cells. rhActivin-A treatment resulted in $\sim 4$ fold increase in invasion of OAW-42 cells compared to controls as shown by matrigel invasion assay (Fig. 7a-b). In contrast, PITX2A-enhanced cell invasiveness was reduced by $~ 50 \%$ on transfection with INHBA-siRNA (Fig. 7a-b). PITX2A increased mRNA levels of MMP9 (Fig. 7c), SNAI1 and ZEB1 (Fig. 7d) that were significantly reduced by transfection with activin-A siRNA. Similarly, the mRNA levels of the mesenchymal marker VIM was up-regulated by $\sim 2.5$ folds on PITX2A over-expression, whereas it decreased drastically upon activin-A knockdown in presence of PITX2A over- 


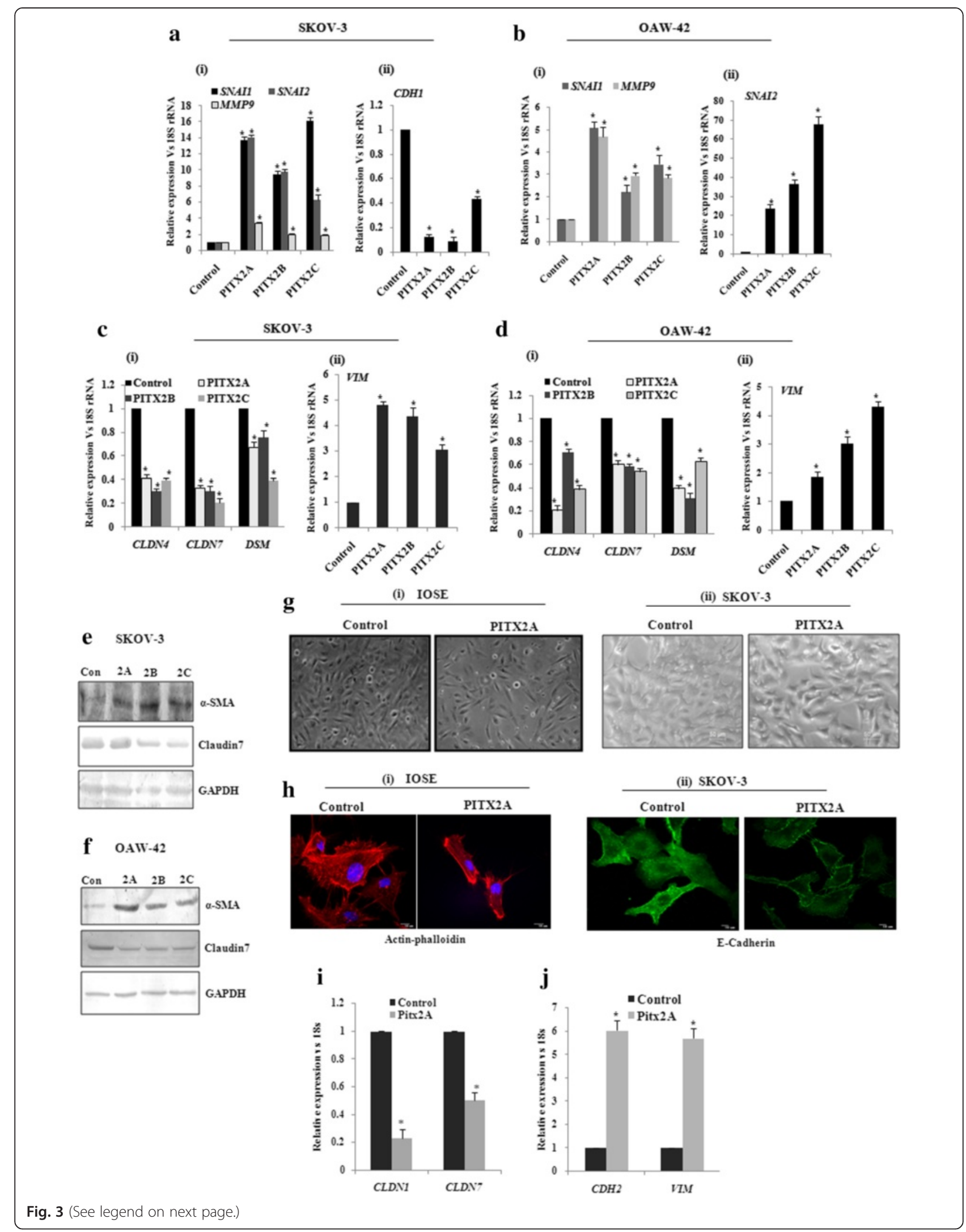


(See figure on previous page.)

Fig. 3 Over-expression of PITX2 affects markers for EMT and invasion in ovarian cancer cells. a-d The expression level of SNA11, SNAI2, MMP9, CLD4, CLD7, DSM and VIM genes were quantified by Q-PCR assay after ectopic over-expression of PITXA/B/C into SKOV-3 (a and c) and OAW-42 (b and $\mathbf{d}$ ) cells. The expression of CDH1 was assessed in SKOV-3 cells (Fig A-ii) upon transient transfection of PITX2 isoforms. The comparative expression of respective genes is shown as relative 'fold' change (mean \pm S.E.M). e-f Western blot analysis of the proteins with respective antibodies was performed with the lysates of PITX2-tranfected SKOV-3 (e) and OAW-42 (f) cells. Here, GAPDH was used as internal loading control. $\mathbf{g}$ Bright field microscopy images exhibit the epithelial phenotype of the control and mesenchymal phenotype of PITX2A-transfected IOSE (G-i) and SKOV3 (G-ii) cells cells. $\mathbf{h}$ Phalloidin staining of IOSE cells (i) and imunofluorescence imaging of E-cadherin was performed for the SKOV-3 cells (ii). i-j Q-PCR assay was performed to check the expression of CLDN1, CLDN7, CDH2 and VIM in PITX2-overexpressed IOSE cells. * represents $p<0.05$

expression (Fig. 7e). Knockdown of INHBA rescued the PITX2A-mediated suppression of the epithelial marker CLDN7 (Fig. 7f).

\section{Discussion}

High mortality rates of ovarian cancer patients are not only due to the rapid resistance acquired by the tumor cells to conventional therapies but also due to their overtly aggressive and invasive behaviour [29]. Metastatic cells undergo various genetic and epigenetic changes that increase motility and invasive behavior [29]. Evidence supports a strong positive role of both TGF- $\beta$ ligands and their receptors in promoting carcinogenesis through invasive transformation. In tumor cells, increased secretion of the TGF- $\beta$ ligands enhance metastasis and promotes tumorigenesis $[30,31]$. The three mammalian isoforms, TGF- $\beta 1 /$ $\beta 2 / \beta 3$, are encoded by different genes which function throughtrans-membrane receptors with intrinsic cytoplasmic serine-threonine kinase domains [32]. Among those, TGF- $\beta 1$ is most frequently up-regulated in tumor cells [33] and is the focus of most studies, including ours.

TGF- $\beta /$ SMAD signalling pathway has been earlier demonstrated to be operational in ovarian cancer cells [34] and our present report demonstrated its activation in human ovarian tumors (Fig. 1). We showed up-regulation of a homeodomain transcription factor, PITX2, in similar tissue sections [28], indicating its possible involvement in ovarian cancer. Recently the association of PITX2 with cancers of thyroid, prostate, colon and breast $[26,27,35]$ has been highlighted. In addition, inactivation of PITX2 leads to apoptosis of pituitary gonadotrophs [36] suggesting an active association between PITX2 and cancer, although no such report is available in the context of ovarian cancer. Considering the importance of the regulation of TGF- $\beta$ pathway by homeodomain proteins including HOXB9 in promoting tumorigenesis [37], we investigated the possible association of PITX2 and TGF- $\beta$ signalling in ovarian cancer. Our experiments demonstrated that PITX2 isoforms differentially enhanced the expression of TGFB1/2/3 genes. In addition, PITX2-activated TGF- $\beta$ signalling pathway (Fig. 1) was evidenced by p-SMAD2 induction as well as its nuclear localization by PITX2-CM in ovarian cancer cells.

We further investigated the role of PITX2-activated TGF- $\beta$ pathway in EMT and invasion, the key steps in ovarian cancer progression [38]. We showed a significant regulatory role of PITX2 in inducing EMT through expression of EMT markers (Fig. 2) and phenotypic changes in PITX2-overexpressed cells. Earlier studies demonstrated the regulatory function of HoxB7 and HoxA10, the homeodomain transcription factors, in controlling EMT [21, 39]. Here we show an important role of PITX2 in promoting EMT. In addition, Snail and Slug are important effectors for invasiveness. They act through transcriptional repression of E-cadherin, thereby [40] facilitating metastasis [41] through basement membrane degradation, associated with lower overall survival in ovarian cancer [42]. Moreover, ectopic expression of Snail or Slug results in enhanced invasiveness and tumorigenicity in the SKOV-3 cells [43]. We showed up-regulation of Snail/Slug and downregulation of E-cadherin upon over-expression of PITX2 isoforms (Fig. 2). The activity of MMPs has been implicated in tumor growth and metastasis through ECM remodelling [44] and can be considered as an independent prognostic marker [45]. We found up-regulation of $M M P 9$ by PITX2 in ovarian cancer cells, suggesting PITX2 as a key regulator of relevant genes that control invasion/metastasis of ovarian cancer cells.

Our data suggests that either recombinant TGF- $\beta 1$ or PITX2 over-expression can induce motility/invasion in ovarian cancer cells (Fig. 4). When PITX2-transfected cells were treated with rhTGF- $\beta 1$, a synergistic activity on cellular invasion was observed. Quite surprisingly, PITX2-transfected cell lysates showed higher level of p-SMAD2 compared to rhTGF- $\beta 1$-treated ones (Fig. 1c-d). We postulated involvement of some other factors upregulated by PITX2-overexpression that could increase p-SMAD2. Indeed, we found activin-A as one such factor that is enhanced by PITX2. In addition, PITX2 binds to the bicoid-like elements present in the promoter of INHBA gene and trans-activates it, enhancing the formation of activin-A (Fig. 3). In ovary, activin is predominantly expressed in the granulosa cell layer of follicles and plays important roles in several physiological processes, including folliculogenesis, steroid hormone production, and oocyte maturation by acting either as a paracrine or autocrine factor [46]. Through the activation of activin signaling mediated by ActRIB-Smad2 system, activin-A facilitates the expression of FSH receptor and aromatase activity which is essential for ovarian granulosa cell function, differentiation 


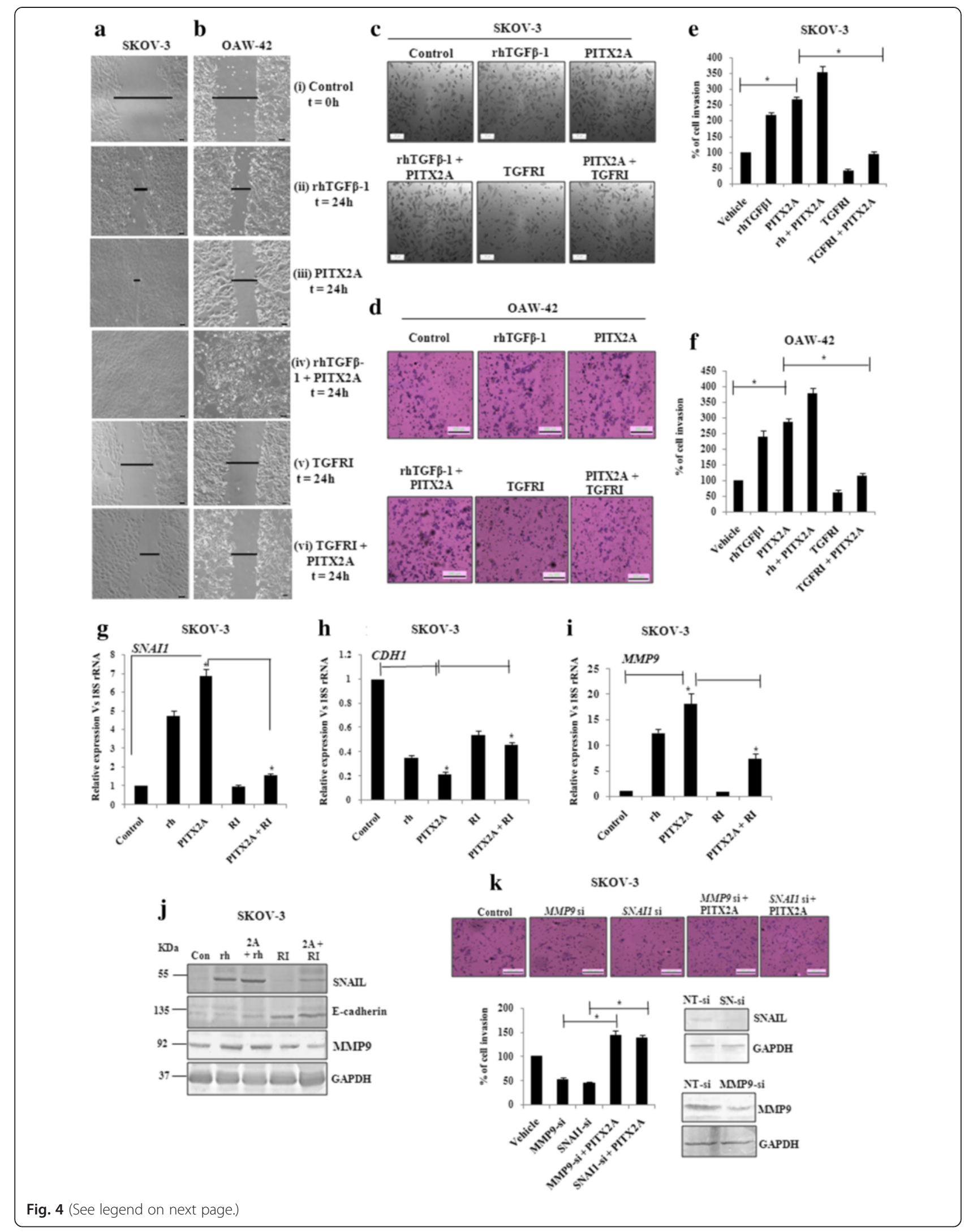


(See figure on previous page.)

Fig. 4 The regulation of invasion and migration is served by PITX2-mediated activation of TGF- $\beta$ signalling pathway. Wound healing assay was performed of SKOV-3 (a) and OAW-42 (b) cells after treatment with rhTGF 31 (ii), transient transfection of PITX2A (iii) and treatment with rhTGF $\beta 1$ (iv) or TGFRI (v) of PITX2-transfected cells in the time course of $24 \mathrm{~h} . \mathrm{T}=0 \mathrm{~h}$ at control cells (i) signifies the time of scratching the cells with pipette tips. The arrows indicate the width of wound and the assay was repeated three times independently. Scale bar: $50 \mu m$. Transwell migration and invasion assay was performed in SKOV-3 (c) and OAW-42 (d) cells after treatment and/or transient transfection as mentioned. Scale bar: 200 $\mu \mathrm{m}$. Cells at three independent fields for each well were counted and plotted with error bar for SKOV-3 (e) and OAW-42 (f) cells. g-i pcDNA3 or PITX2A-transfected SKOV-3 cells were treated with rhTGF $\beta 1(10 \mathrm{ng} / \mathrm{ml})$ or TGFRI $(20 \mathrm{ng} / \mathrm{ml})$ followed by isolation of RNA and Q-PCR with the primers of SNAl1 (g), CDH1 (h) and MMP9 (i). Relative gene expression is indicated as 'fold' change in the Y-axis (mean \pm SEM). * represents $p<0.01$. $\mathbf{j}$ Lysates of the cells transiently transfected and/or treated as indicated were immunoblotted with respective antibodies and the representative gel image was shown. $\mathbf{k}$ Transwell invasion assay was performed with SKOV-3 cells after transient transfection as mentioned (top). Cells at three independent fields for each well were counted and were plotted with error bar (bottom). The efficiency in knocking down the expression of SNAIL and MMP9 proteins by SNAI-(SN)-si and MMP9-si respectively was verified by Western blot of the transfected cell lysates with respective antibodies. Here, GAPDH was used as loading control (bottom)

and folliculogenesis $[47,48]$. Both experimental and clinical studies suggest the elevated level of activin-A in the serum of granulosa cell tumor patients [49]. Our finding could add another dimention to the function and regulation of activin-A, particularly, in epithelial ovarian cancer.

We showed earlier that PITX2 interacts with and regulates, FGF16, a prime inducer of invasion of ovarian cancer cells [28]. We also showed significant involvement of PITX2 in regulating the Wnt signalling pathway that induces proliferation of ovarian cancer cells [50], creating an auto-regulatory feedback loop. The present study is the first comprehensive investigation on the regulatory role of PITX2 on invasive behavior in ovarian carcinoma cells. TGF- $\beta$ pathway is considered to be a prime regulator in inducing invasion of ovarian cancer cells. Here, we identified a novel regulatory role of PITX2 through expression of both TGFB and INHBA genes. The involvement of activin$\mathrm{A}$, the homodimer form of INHBA, in inducing invasion leading to epithelial ovarian cancer progression (apart from GCT) has been demonstrated for the first time in this study. Thus, it is imperative to say that PITX2 appears to act as an important regulatory protein that controls initiation and progression of epithlial ovarian cancer. Further study may explore the possible involvement of PITX2 in GCT. TGF- $\beta$ has been shown to synergize with oncogenic pathways. Evidence suggests that Wnts can also cooperate with other signaling pathways during tumorigenesis. PITX2 lies upstream of these two pathways, thus playing a significant role in tumorigenesis and metastasis.

\section{Conclusion}

The major findings of our study are: a) PITX2 up-regulates the expression of ligand genes of TGF- $\beta$ superfamily, TGFB and INHBA followed by induction of SMAD2/3-dependent TGF- $\beta$ signalling pathway; $b)$ through the activation of TGF- $\beta$ pathway, PITX2 regulates the expression of genes that enhances invasion and EMT of ovarian cancer cells; c) This is the first report to show the direct involvement of activin-A, the homodimer form of INHBA, in promoting invasion and EMT of both non-cancerous and cancerous cells. (d) Overall this present report is first of its kind to show the direct involvement of a homeodomain transcription factor, PITX2, in the progression of ovarian cancer.

\section{Methods}

\section{Cell culture, treatment of growth factor and inhibitors}

Human ovarian adenocarcinoma cells, SKOV-3 (ATCC, USA) and OAW-42 (Sigma-Aldrich; USA) were maintained in McCoy's 5A (Sigma) and DMEM (Invitrogen) respectively; both supplemented with $10 \%$ fetal bovine serum (FBS, Invitrogen, USA), $100 \mathrm{U} / \mathrm{ml}$ penicillin and $100 \mu \mathrm{g} / \mathrm{ml}$ streptomycin both Invitrogen; [51]. Human immortalized ovarian surface epithelial cells, IOSE (a kind gift from Drs. N. Aueresperg and Clara Salamanca, Vancouver, Canada) was maintained in Medium199 (Invitrogen) and MCDB105 (Sigma-Aldrich; USA) in 1:1 ratio supplemented with $10 \% \mathrm{FBS}, 100 \mathrm{U} / \mathrm{ml}$ penicillin and $100 \mu \mathrm{g} / \mathrm{ml}$ streptomycin. Here, the low-passage cultures of human ovarian surface epithelium cells (isolated by scraping from human ovarian surface tissue) were immortalized by transfecting with SV40 large-T antigen viral particles [52].

Human recombinant TGF- $\beta 1$ (rhTGF- $\beta 1$; Calbiochem, Germany) was used at $10 \mathrm{ng} / \mathrm{ml}$ for $30 \mathrm{~min}$ and $8 \mathrm{~h}$ for Western-blot and Q-PCR assay respectively. TGF- $\beta$ receptorI kinase inhibitor (TGFRI; $20 \mathrm{ng} / \mathrm{ml}$ ) was procured from Calbiochem (cat. no. 616451). Recombinant human Activin-A (rhActivin-A; ACRO Biosystems) was used at $100 \mathrm{ng} / \mathrm{ml}$ for $30 \mathrm{~min}$ and $24 \mathrm{~h}$ for Western-blot and Q-PCR assay respectively. Activin-A neutralizing antibody (Novus Biologicals) was used at a concentration of $2 \mu \mathrm{g} / \mathrm{ml}$. Prior to each treatment, the cells were serum-starved for $16 \mathrm{~h}$ and the control cells were treated with vehicles (0.1\% BSA in $1 \mathrm{X}$ PBS or DMSO).

\section{Expression and reporter constructs}

The $1.7 \mathrm{~kb}$ upstream promoter region of INHBA gene was amplified by PCR using human genomic DNA as template and then cloned into pGL3 basic vector (Promega) at MluI/HindIII site. The primer sequences used 


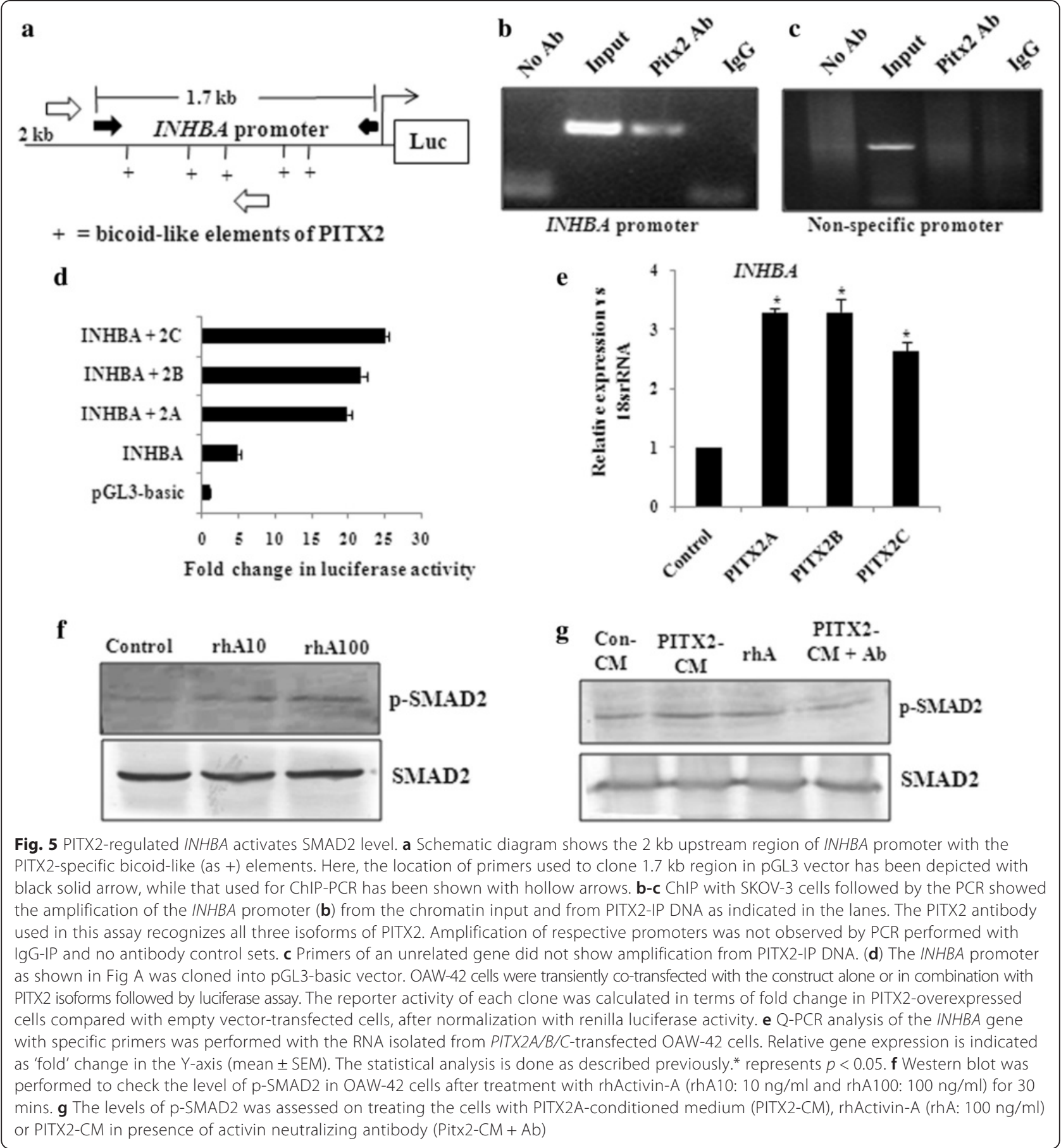

to clone the promoters are mentioned in Table 1, where the restriction enzyme sites are underlined. All constructs were sequenced by ABI Prism Automated DNA Sequencer (Perkin Elmer, USA). Sequence alignment and data analysis were performed through BLAST search (NCBI Gen Bank). The TGF- $\beta$ inducible p3TP-Lux luciferase reporter vector was procured from Addgene, USA. pRL-CMV (Promega, USA) vector with Renilla-luciferase gene was used to normalise the luciferase activity. Expression plasmids of three isoforms of PITX2 (PITX2A/B/C) were described earlier [28]. To evaluate the expression profile of the TGFB genes as well as the genes associated with invasion and EMT, we performed over-expression of three isoforms of PITX2 $(P I T X 2 A / B / C)$. As a similar trend was observed in the change in gene expression by these isoforms, we used PITX2A isoform as representative in the subsequent physiological experiments like activation of TGF- $\beta$ pathway, 


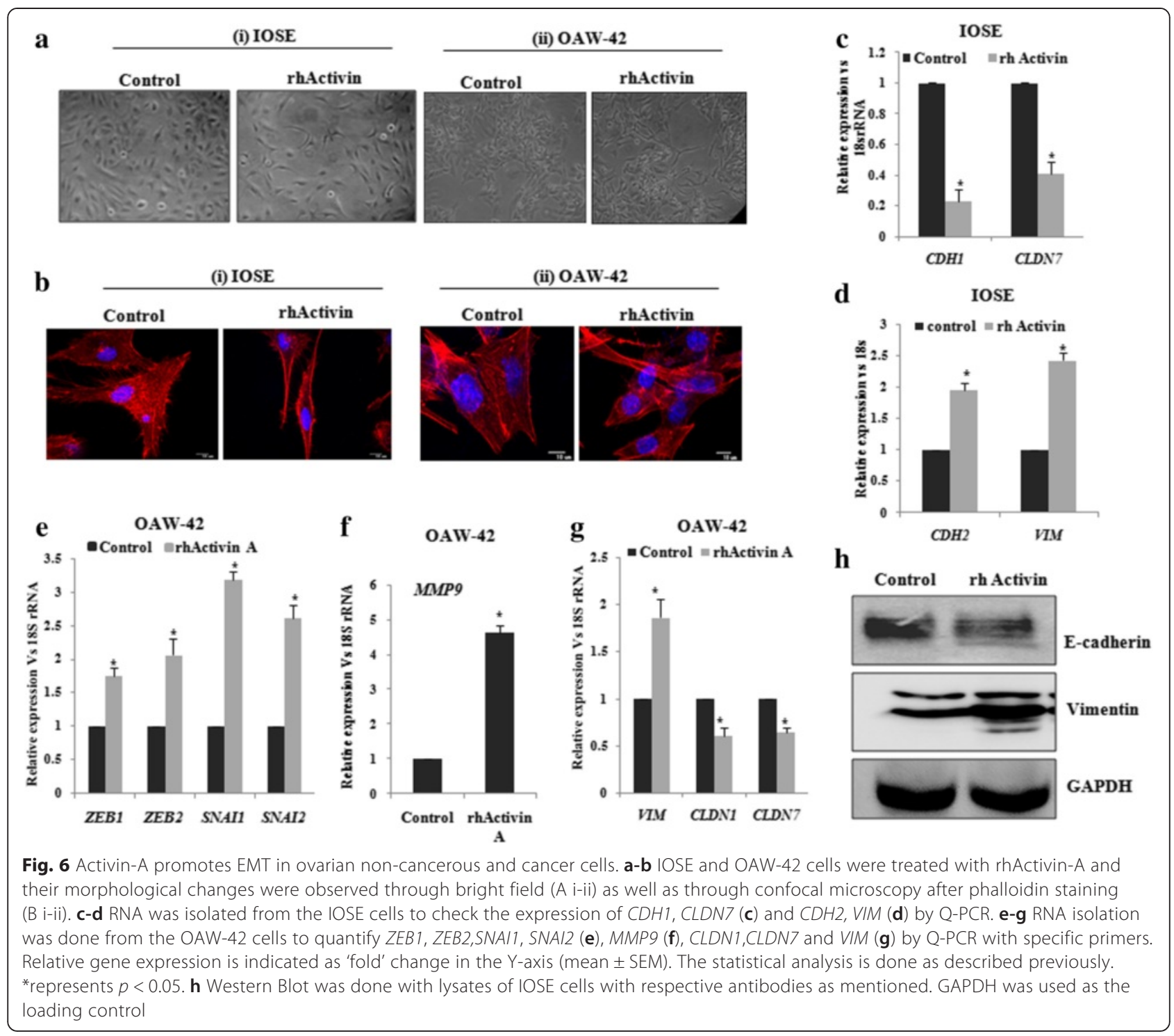

matrigel invasion, wound healing and cell proliferation assay etc.

\section{Transient transfection and luciferase assay}

For reporter assay, $5 \times 10^{4}$ cells were seeded on 12-well culture plates. After $24 \mathrm{~h}$, p3TP-Lux vector $(0.4 \mu \mathrm{g})$ was transiently transfected alone or along with PITX2 expression vectors $(0.4 \mu \mathrm{g})$ with Lipofectamine 2000 (Invitrogen). After $4 \mathrm{~h}$ of transfection, the medium was replaced with fresh incomplete one supplemented with either TGFRI or DMSO for next $16 \mathrm{~h}$. Each transfection was normalized with pRL-CMV vector $(0.04 \mu \mathrm{g})$. In the following day, cells were harvested and firefly/renilla luciferase activity was determined [50]. The transfection of pGL3-reporter vectors and the subsequent assay was performed following the same protocol. Each transfection was performed in triplicate and the experiments were repeated thrice.

To over-express PITX2 isoforms, $1 \mu \mathrm{g}$ of expression constructs were transfected per $10^{5}$ cells/well in 6-well plate using Lipofectamine 2000 (Invitrogen). After $24 \mathrm{~h}$ and $48 \mathrm{~h}$ of transfection, the cells were harvested to isolate RNA and protein respectively. For the treatment of rhTGF- $\beta 1 /$ TGFRI, the medium was replaced after $4 \mathrm{~h}$ of PITX2 transfection with fresh one supplemented with these factors. The cells were harvested after $16 \mathrm{~h}$ for RNA/protein isolation. To collect conditioned medium (CM), PITX2A was transiently transfected as mentioned earlier. After $6 \mathrm{~h}$, the medium was replaced with fresh serum-free one, which was collected after $24 \mathrm{~h}$ of transfection and added directly or in combination with rhTGF- $\beta 1 /$ TGFR 1 to the freshly plated cells. The treated cells were harvested after $2 \mathrm{~h}$ for protein 


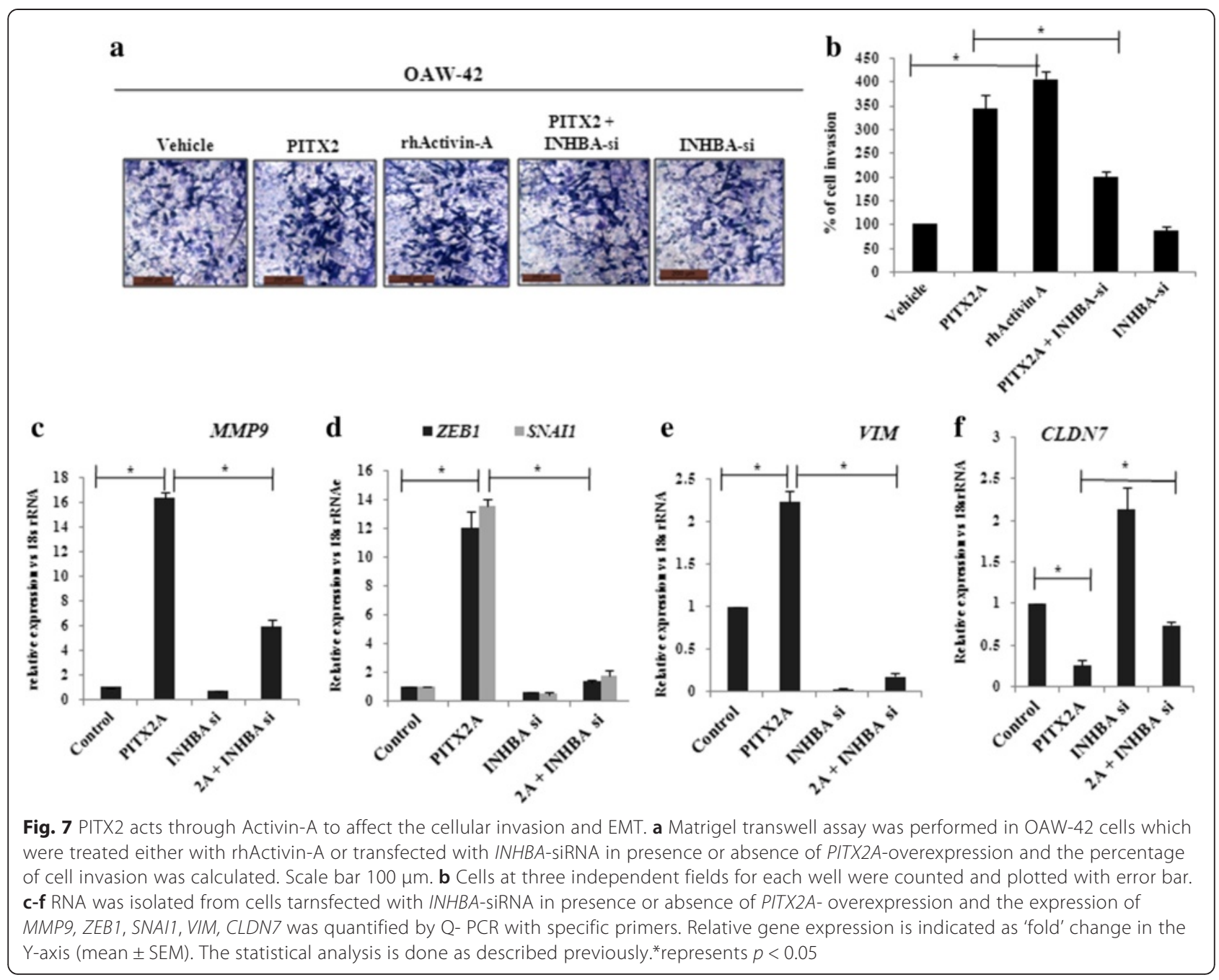

isolation. The control cells were transfected with empty vector (pcDNA3.1 Myc-His) in each case.

\section{siRNA and transfection}

The siRNAs against SNAI1, MMP9 and INHBA (all from Santa Cruz Biotechnology, USA) were used at $20 \mathrm{nM}$ /well using $2 \mu$ l Lipofectamine RNAiMAX (Invitrogen) in the cells seeded in 6-well plates. The RNA interference against PITX2 was carried out by the ON-TARGET plus SMART pool siRNA at $20 \mathrm{nM} /$ well using $2 \mu \mathrm{l}$ of Dharmafect-1 transfection reagent (Dharmacon) in cells seeded in 6-well culture plates. After $48 \mathrm{~h}$ of transfection, the cells were harvested for RNA/protein isolation. When required, rhTGF- $\beta 1$ was added after $24 \mathrm{~h}$ of respective siRNA transfection into the cells.

\section{Quantitative Real-time RT-PCR (Q-PCR)}

Total RNA was isolated from ovarian cell lines using TRIreagent (Sigma) following the standard protocol [53]. First-strand cDNA synthesis followed by Q-PCR assay was performed as described [28]. The comparative $C_{T}$ method $\left(\Delta \Delta C_{\mathrm{T}}\right)$ was used to measure relative gene expression where the fold enrichment was calculated as: 2

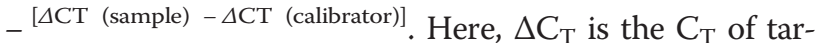
get gene subtracted from the $\mathrm{C}_{\mathrm{T}}$ of the housekeeping gene [50]. The primer sequences are mentioned in Table 2.

Table 1 The sequence of the oligonucleotide primers used to amplify specific regions of the promoter

\begin{tabular}{llll}
\hline $\begin{array}{l}\text { Gene Name } \\
\& \text { ACc no }\end{array}$ & Region amplified & Forward primer (5'- 3') & Reverse primer (5'- 3') \\
\hline INHBA; & $41702063-41700378$ & GGACGCGTGAACGCTTAACAGATGGAC GGAAGCTTGCAAAAGTTGTTGTGATTGC & 1.7 \\
\hline NC_000007.14 & & & \\
\hline
\end{tabular}


Table 2 The sequence, respective amplicon size and Tm of the oligonucleotide primers used in Q-PCR

\begin{tabular}{|c|c|c|c|c|}
\hline Gene Name & Forward primer $\left(5^{\prime}-3^{\prime}\right)$ & Reverse primer $\left(5^{\prime}-3^{\prime}\right)$ & Amplicon size (bp) & $\operatorname{Tm}\left({ }^{\circ} \mathrm{C}\right)$ \\
\hline $18 \mathrm{~S}$ rRNA & GATTCCGTGGGTGGTGGTGC & AAGAAGTTGGGGGACGCCGA & 134 & 60 \\
\hline POLR2A & TGGACCCACCGGCATGTTCT & GCCCCTGGGGTCATTCCACT & 141 & 60 \\
\hline CLDN4 & GGCTGCTITGCTGCAACT & CAGAGCGGGCAGCAGAATAC & 110 & 60 \\
\hline CLDN7 & GTGGCAGATGAGCTCCTATGC & CATCCACAGCCCCTTGTACA & 80 & 60 \\
\hline DSM & GCAGCAAAGGGCGGAGAT & TGTTAATGTGCTGCTCCACTGA & 80 & 60 \\
\hline VIM & ACACCCTGCAATCTTTCAGACA & GATTCCACTITGCGTTCAAGGT & 80 & 60 \\
\hline FN1 & CCTTCATGGCAGCGGTT & AGCGTCCTAAAGACTCCATGATCT & 94 & 60 \\
\hline PITX2 & CGCGAAGAAATCGCTGTGT & CGACGATTCTTGAACCAAACC & 78 & 58 \\
\hline TGFB1 & GTGACAGCAGGGATAACACACTG & CATGAATGGTGGCCAGGTC & 80 & 60 \\
\hline TGFB2 & GCTGAGCGCTTTTCTGATCCT & CGAGTGTGCTGCAGGTAGACA & 80 & 60 \\
\hline TFGB3 & CACCACAACCCTCATCTAATCCT & CCTGGCCCGGGTTGTC & 100 & 60 \\
\hline SNAl1 & TCGGAAGCCTAACTACAGCGA & AGATGAGCATTGGCAGCGAG & 140 & 60 \\
\hline SNAI2 & ATGAGGAATCTGGCTGCTGT & CAGGAGAAAATGCCTITGGA & 119 & 60 \\
\hline $\mathrm{CDH} 1$ & GTCACTGACACCAACGATAATCT & TTCAGTGTGGTGATTACGACGTA & 100 & 60 \\
\hline MMP9 & ACCTCGAACTITGACAGCGAC & GAGGAATGATCTAAGCCCAGC & 113 & 60 \\
\hline INHBA & GTGAGTGCCCGAGCCATATAG & CATGCGGTAGTGGTTGATGACT & 80 & 60 \\
\hline $\mathrm{CDH} 2$ & CCATCAAGCCTGTGGGAATC & GCAGATCGGACCGGATACTG & 76 & 60 \\
\hline ZEB1 & CAATGATCAGCCTCAATCTGCA & CCATTGGTGGTTGATCCCA & 117 & 60 \\
\hline ZEB2 & AAGCCCCATCAACCCATACAAG & AAATTCCTGAGGAAGGCCCA & 124 & 60 \\
\hline
\end{tabular}

\section{Chromatin-immunoprecipitation (ChIP)}

ChIP with SKOV-3 cells was performed following the methods described earlier [50]. For ChIP-PCR, the immunoprecipitated (IP) and input DNA were used at equal quantity following the conditions: $95^{\circ} \mathrm{C}$ for $30 \mathrm{~s}$, annealing at specific temp for $30 \mathrm{~s}$ and extension at $72{ }^{\circ} \mathrm{C}$ for $30 \mathrm{~s}$, for 30 cycles. The information of the primers is shown in Table 3.

\section{Western blot analysis}

Cell lysis and protein extraction was performed as described previously [51] and subjected to immunoblotting with antibodies specific for the proteins including, PITX2 (Chemicon, 1:1000), $\alpha$-SMA (Sigma; 1:1000 dilution), claudin-7, MMP9 (both Santa Cruz; 1:1000 dilution), GAPDH (1:3000), E-cadherin, SNAIL, vimentin, p-SMAD2 and SMAD2 (all 1:2000 dilution; all from Cell signalling technology, USA).

\section{Confocal microscopy}

Immunofluorescence staining with anti-p SMAD2 (1:100) E-cadherin (1:100) and PITX2 (1:100) antibodies followed by Alexa-fluor 488-conjugated secondary antibody was performed as described previously [28]. For phalloidin staining $10^{5}$ cells/well were plated in 6-well plate. After $24 \mathrm{~h}$ of PITX2A transfection or rhActivin-A treatment, actin filament bundle formation was observed by phalloidin staining as mentioned previously [54] followed by imaging with confocal microscopy.

\section{Wound healing assay}

Serum-starved cells at $70 \%$ confluency were transfected with PITX2A-construct. After $4 \mathrm{~h}$, medium was replaced by fresh and incomplete one supplemented with rhTGF$\beta 1 /$ TGFRI. In additional experiment, treatment was also given in other set of serum-starved cells to check the effect of only TGF- $\beta 1 /$ TGFRI on migration. Scratching was carried out with a $200 \mu \mathrm{l}$ pipette tip prior to the treatment and mentioned as $\mathrm{t}=0 \mathrm{~h}$ at the figure. Cells were washed several times with PBS to remove the detached ones and supplied with new growth medium. Photographs of the scratches were taken at 0 and $24 \mathrm{~h}$ using an inverted microscope (Leica) equipped with a Scion digital camera and in-built software (Leica application suite v3.0).

Table 3 The sequence, respective amplicon size and Tm of the oligonucleotide primers used in ChIP-PCR

\begin{tabular}{llllll}
\hline Gene Name \& Acc no & Region amplified & Forward primer (5'- 3') & Reverse primer (5'- 3') & Amplicon size (kb) & Tm ( $\left.{ }^{\circ} \mathrm{C}\right)$ \\
\hline INHBA; NC_000007.14 & $41702097-41701831$ & GGCTTATGTGTGGGAAAGAA & ACCAGTGCATTCATAGACAG & 265 & 55.5 \\
\hline
\end{tabular}




\section{In vitro invasion assay}

Transwell membranes coated with Matrigel (BD Biosciences, USA) were used to assay in vitro invasion as mentioned previously [53]. In brief, $2.5 \times 10^{5}$ cells were seeded in the upper chamber in serum-free medium and FBS or rhTGF- $\beta 1 /$ TGFRI was added in the lower chamber. To check the effect of PITX2, MMP9 and SNAIL on TGF$\beta$-mediated invasion, cells were transiently transfected with respective construct or siRNAs on previous day, allowed to recover overnight and then serum-starved for additional $16 \mathrm{~h}$. The cells were then trypsinized, counted and equal number of transfected cells were added in the upper chamber and allowed to invade in presence of TGF- $\beta$ or TGFRI.To understand the role of activin-A in PITX2mediated cell invasion, the cells were transiently transfected with PITX2 expression construct or INHBA-siRNAs or both on previous day, allowed to recover overnight and then serum-starved for additional $16 \mathrm{~h}$. The cells were then trypsinized, counted and equal number of transfected cells were added in the upper chamber and allowed to invade in presence or absence of rhActivin-A. After incubating for $22 \mathrm{~h}$ at $37{ }^{\circ} \mathrm{C}$ in $5 \% \mathrm{CO}_{2}$, the invaded cells were fixed, stained and counted under microscope. Three independent experiments were performed followed by statistical analysis.

\section{Immunohistochemistry (IHC) with immunofluorescence (IF)-based detection}

Tissue sample blocks used for IHC were archival materials provided by the Department of Pathology, Institute of Post Graduate Medical Education and Research and SSKM Hospital, Kolkata, India. Isolated tissues were fixed, processed, and sectioned as mentioned earlier [55]. The sections were then blocked in $5 \%$ BSA in 1XTBS-T for $30 \mathrm{~min}$ and incubated for $2 \mathrm{~h}$ with the anti-pSMAD2 (1:100) and antibody diluted in 1XTBS containing $0.1 \%$ BSA. The slides were then washed and incubated for $1 \mathrm{~h}$ with the secondary antibody (Alexa Fluor-488; 1:500) followed by staining with DAPI. The IF-staining was performed in all collected samples and the representative images have been shown.

\section{Statistical analysis}

All data were expressed as mean \pm SEM and the \pm SEM are represented by error bars. The statistical significance was calculated by two-tailed Student's $t$-test. $p<0.05$ was considered as significant. The experiments were done at least 3 times in duplicate unless otherwise stated.

\section{Additional file}

Additional file 1: Figure S1. The expression of PITX2 is up-regulated in human ovarian cancer. (A) The level of PITX2 was observed by IHC in human ovarian tissue-sections with specific antibody followed by Alexa Fluor-488 (green) of low malignant potential $(i ; n=20)$ and high malignant potential metastatic adenocarcinoma patients (ii; $n=20$ ) The DAPI-stained nuclei and the merged images were also shown. Scale bar, $10 \mu \mathrm{m}$. (TIFF $28495 \mathrm{~kb}$ )

\section{Abbreviation}

DAPI: 4', 6-Diamidino-2-phenylindole; TGF: Transforming growth factor; MMP: Matrix metalloprotease; SMAD: Mothers against decapentaplegic, Drosophila; EMT: Epithelial-mesenchymal transition; GAPDH: Glyceraldehyde-3 phosphate dehydrogenase; ECM: Extracellular matrix; SMA: Smooth muscle actin; CLDN: Claudin; CDH1: E-cadherin; CDH2: N-cadherin; SNAl1: SNAIL; SNAI2: SLUG; INHBA: activin-A; IOSE: Immortalized ovarian surface epithelium.

\section{Competing interests}

The authors declare that they have no competing interests.

\section{Authors' contributions}

$\mathrm{MB}$ designed and performed the experiments and drafted the manuscript. RB planned and performed immunodetection and imaging, Q-PCR and matrigel assay. UR did the confocal imaging, Q-PCR and immunodetection. SNM partly drafted and corrected the manuscript. UC collected the human tissue samples and processed. SSR conceived the study, designed the experiments and drafted the manuscript. All authors read and approved the final manuscript.

\section{Acknowledgements}

We thankfully acknowledge Council of Scientific and Industrial Research (CSIR, project No. BSC 0101 and BSC 0206), Govt. of India, for funding. MB and RB are the recipient of fellowship from CSIR, Govt. of India [award no. 10-2(5)/2007(II)-E.UII and 31/002(0941)/2013-EMR-1 respectively]. UR is a recipient of fellowship from UGC, Govt. of India [award no.19-06/2011(i)EU-IV]. The IOSE cells were a kind gift from Dr. Clara Salamanca, as mentioned in the methods section. The technical assistance of Prabir Kumar Dey (CSIR-IICB) is gratefully acknowledged. Other members of SSR laboratory are thankfully acknowledged for their co-operation.

\section{Author details}

${ }^{1}$ Cell Biology and Physiology Division, CSIR-Indian Institute of Chemical Biology, Council of Scientific and Industrial Research, 4 Raja S. C. Mullick Road, Kolkata 700032, India. ${ }^{2}$ Department of Endocrinology and Metabolism, IPGMER and SSKM Hospital, 244 AJC Bose Road, Kolkata, India. ${ }^{3}$ Department of Pathology, IPGMER and SSKM Hospital, 244 AJC Bose Road, Kolkata, India.

Received: 18 March 2015 Accepted: 12 August 2015

Published online: 23 August 2015

\section{References}

1. Yap TA, Carden CP, Kaye SB. Beyond chemotherapy: targeted therapies in ovarian cancer. Nat Rev Cancer. 2009;9:167-81.

2. Scully RE. Pathology of ovarian cancer precursors. J Cell Biochem Suppl. 1995;23:208-18.

3. Gotzmann J, Mikula M, EgerSchulte-Hermann AR, Foisner R, Beug H, Mikulits W. Molecular aspects of epithelial cell plasticity: implications for local tumour invasion and metastasis. Mutat Res. 2004;566:9-20.

4. Akhurst RJ, Derynck R. TGF-beta signaling in cancer-a double-edged sword Trends Cell Biol. 2001;11:S44-51.

5. Shi Y, Massagué J. Mechanisms of TGF-beta signaling from cell membrane to the nucleus. Cell. 2003;113:685-700.

6. Burger HG. Inhibin. Rep Med Rev. 1992;1:1-20.

7. De Kretser DM, Robertson DM. The isolation and physiology of inhibin and related proteins. Biol Reprod. 1989;40:33-47.

8. Choi YL, Kim HS, Ahn G. Immunoexpression of inhibin alpha subunit, inhibin/activin betaA subunit and CD99 in ovarian tumors. Arch Pathol Lab Med. 2000;124:563-9.

9. Petraglia F, Luisi S, Pautier P, Sabourin JC, Rey R, Lhomme C, et al. Inhibin B is the major form of inhibin/activin family secreted by granulosa cell tumors. J Clin Endocrinol Metab. 1998;83:1029-32.

10. Yoshinaga K, Mimori K, Inoue H, Kamohara Y, Yamashita K, Tanaka F, et al. Clinical significance of the expression of activin $\mathrm{A}$ in esophageal carcinoma. Int J Oncol. 2003:22:75-80.

11. Wildi S, Kleeff J, Maruyama H, Maurer CA, Büchler MW, Korc M. Overexpression of activin A in stage IV colorectal cancer. Gut. 2001;49:409-17. 
12. Okano M, Yamamoto H, Ohkuma H, Kano Y, Kim H, Nishikawa S, et al. Significance of INHBA expression in human colorectal cancer. Oncol Rep. 2013;30:2903-8.

13. Petersen OW, Nielsen HL, Gudjonsson T, Villadsen RF, Rank E, Niebuhr MJ, et al. Epithelial to mesenchymal transition in human breast cancer can provide a nonmalignant stroma. Am J Pathol. 2003;162:391-402.

14. Thiery JP. Epithelial-mesenchymal transitions in tumour progression. Nat Rev Cancer. 2002;2:442-54.

15. Peinado H, Olmeda D, Cano A. Snail, Zeb and bHLH factors in tumour progression: an alliance against the epithelial phenotype? Nat Rev Cancer. 2007;7:415-28

16. Sun L, Diamond ME, Ottaviano AJ, Joseph MJ, Ananthanarayan V, Munshi HG. Transforming growth factor-beta 1 promotes matrix metalloproteinase 9-mediated oral cancer invasion through snail expression. Mol Cancer Res. 2008;6:10-20.

17. Abate-Shen C, Shen MM, Gelmann E. Integrating differentiation and cancer: the Nkx3.1 homeobox gene in prostate organogenesis and carcinogenesis. Differentiation. 2008;76:717-27.

18. Raman V, Martensen SA, Reisman D, Evron E, Odenwald WF, Jaffee E, et al. Compromised HOXA5 function can limit p53 expression in human breast tumours. Nature. 2000;405:974-8.

19. Crijns AP, de Graeff P, Geerts D, Ten Hoor KA, Hollema H, Van der Sluis T et al. MEIS and PBX homeobox proteins in ovarian cancer. Eur J Cancer. 2007:43:2495-505.

20. Tan Y, Cheung M, Pei J, Menges CW, Godwin AK, Testa JR. Upregulation of DLX5 promotes ovarian cancer cell proliferation by enhancing IRS-2-AKT signalling. Cancer Res. 2010;70:9197-206.

21. Wu X, Chen H, Parker B, Rubin E, Zhu T, Lee JS. HOXB7, a homeodomain protein, is overexpressed in breast cancer and confers epithelial-mesenchymal transition. Cancer Res. 2006;66:9527-34.

22. Hayashi M, Maeda S, Aburatani H, Kitamura K, Miyoshi H, Miyazono K, et al. PITX2 prevents osteoblastic trans differentiation of myoblasts by bone morphogenetic proteins. J Biol Chem. 2008;283:557-65.

23. Kioussi C, Briata P, Baek SH, Rose DW, Hamblet NS, Herman T et al. Identification of a Wnt/Dvl/[beta]-catenin PITX2 pathway mediating celltype-specific proliferation during development. Cell. 2002;111:673-85.

24. Lin CR, Kioussi C, O'Connell S, Briata P, Szeto D, Liu F, et al. Pitx2 regulates lung asymmetry, cardiac positioning and pituitary and tooth morphogenesis. Nature. 1999;401:279-82.

25. Cox CJ, Espinoza HM, McWilliams B, Chappell K, Morton L, Hjalt TA, et al. Differential regulation of gene expression by PITX2 isoforms. J Biol Chem. 2002;277:25001-10

26. Nimmrich I, Sieuwerts AM, Meijer-van Gelder ME, Schwope I, Bolt-de Vries J, Harbeck N, et al. DNA hypermethylation of PITX2 is a marker of poor prognosis in untreated lymph node-negative hormone receptor-positive breast cancer patients. Breast Cancer Res Treat. 2008;111:429-37.

27. Hirose H, Ishii H, Mimori K, Tanaka F, Takemasa I, Mizushima T, et al. The significance of PITX2 overexpression in human colorectal cancer. Ann Surg Oncol. 2011;18:3005-12.

28. Basu M, Mukhopadyay S, Chatterjee U, Roy SS. FGF16 promotes invasive behavior of SKOV-3 ovarian cancer cells through the activation of MAPK signaling pathway. J Biol Chem. 2014;289:1415-28.

29. DeVita VT, Hellman S, Rosenberg SA. Cancer: principles and practice of oncology. 6th ed. New York: Lippincott-Raven; 2001.

30. Akhurst RJ, Balmain A. Genetic events and the role of TGF beta in epithelia tumour progression. J Pathol. 1999;187:82-90.

31. Chen $\mathrm{RH}$, Ebner $\mathrm{R}$, Derynck $\mathrm{R}$. Inactivation of the type II receptor reveals two receptor pathways for the diverse TGF-beta activities. Science. 1993;260:1335-8.

32. Massagué J. TGF- $\beta$ signal transduction. Annu Rev Biochem. 1998;67:753-91.

33. Derynck R, Goeddel DV, Ullrich A, Gutterman JU, Williams RD, Bringman TS, et al. Synthesis of messenger RNAs for transforming growth factors a and $\beta$ and the epidermal growth factor receptor by human tumors. Cancer Res. 1987:47:707-12.

34. Dunfield LD, Dwyer EJ, Nachtigal MW. TGF beta-induced Smad signaling remains intact in primary human ovarian cancer cells. Endocrinology. 2002;143:1174-81.

35. Huang Y, Guigon CJ, Fan J, Cheng SY, Zhu GZ. Pituitary homeobox 2 (PITX2) promotes thyroid carcinogenesis by activation of cyclin D2. Cell Cycle. 2010;9:1333-41.
36. Acunzo J, Roche C, Defilles C, Thirion S, Quentien MH, Figarella-Branger D, et al. Inactivation of PITX2 transcription factor induced apoptosis of gonadotroph tumoral cells. Endocrinology. 2011;152:3884-92.

37. Hayashida T, Takahashi F, Chiba N, Brachtel E, Takahashi M, Godin-Heymann $\mathrm{N}$, et al. HOXB9, a gene overexpressed in breast cancer, promotes tumorigenicity and lung metastasis. Proc Natl Acad Sci U S A. 2010;107:1100-5.

38. Lee JM, Dedhar S, Kalluri R, Thompson EW. The epithelial-mesenchymal transition: new insights in signaling, development, and disease. J Cell Biol. 2006;172:973-81.

39. Yoshida H, Broaddus R, Cheng W, Xie S, Naora H. Deregulation of the HOXA10 homeobox gene in endometrial carcinoma: role in epithelial-mesenchymal transition. Cancer Res. 2006;66:889-97.

40. Batlle E, Sancho E, Francí C, Domínguez D, Monfar M, Baulida J, et al. The transcription factor snail is a repressor of E-cadherin gene expression in epithelial tumour cells. Nat Cell Biol. 2000;2:84-9.

41. Vleminckx K, Vakaet Jr L, Mareel M, Fiers W, van Roy F. Genetic manipulation of E-cadherin expression by epithelial tumor cells reveals an invasion suppressor role. Cell. 1991;66:107-19.

42. Blechschmidt K, Sassen S, Schmalfeldt B, Schuster T, Ho"fler H, Becker KF. The E-cadherin repressor Snail is associated with lower overall survival of ovarian cancer patients. Br J Cancer. 2008;98:489-95.

43. Kurrey NK, Amit K, Bapat SA. Snail and Slug are major determinants of ovarian cancer invasiveness at the transcription level. Gynecol Oncol. 2005;97:155-65.

44. Roy R, Yang J, Moses MA. Matrix metalloproteinases as novel biomarkers and potential therapeutic targets in human cancer. J Clin Oncol. 2009;27:5287-97.

45. Lengyel E, Schmalfeldt B, Konik E, Späthe K, Härting K, Fenn A, et al. Expression of latent matrix metalloproteinase 9 (MMP-9) predicts survival in advanced ovarian cancer. Gynecol Oncol. 2001;82:291-8.

46. Peng C, Mukai ST. Activins and their receptors in female reproduction. Biochem Cell Biol. 2000:78:261-79.

47. Mukasa C, Nomura M, Tanaka T, Tanaka K, Nishi Y, Okabe T, et al. Activin signaling through type IB activin receptor stimulates aromatase activity in the ovarian granulosa cell-like human granulosa (KGN) cells. Endocrinology. 2003:144:1603-11.

48. Nomura M, Sakamoto R, Morinaga H, Wang L, Mukasa C, Takayanagi R. Activin stimulates CYP19A gene expression in human ovarian granulosa cell-like KGN cells via the Smad2 signaling pathway. Biochem Biophys Res Commun. 2013:436:443-8.

49. Ciriş $M$, Erhan $Y$, Zekioglu $O$, Bayramoglu $H$. Inhibin alpha and beta expression in ovarian stromal tumors and their histological equivalences. Acta Obstet Gynecol Scand. 2004;83:491-6.

50. Basu M, Roy SS. Wnt/ß-catenin pathway is regulated by PITX2 homeodomain protein and thus contributes to the proliferation of human ovarian adenocarcinoma cell, SKOV-3. J Biol Chem. 2013;288:4355-67.

51. Ghosh S, Basu M, Roy SS. ETS-1 regulates vascular endothelial growth factorinduced matrix metalloproteinase-9 and matrix metalloproteinase-13 expression in human ovarian carcinoma cell SKOV3. J Biol Chem 2012, 287:15001-15.

52. Kruk PA, Maines-Bandiera SL, Auersperg N. A simplified method to culture human ovarian surface epithelium. Lab Invest 1990, 63:132-36.

53. Ghosh P, Saha SK, Nandi SS, Bhattacharya S, Roy SS. Involvement of Pitx2, a homeodomain transcription factor, in hypothyroidism associated reproductive disorders. Cell Physiol Biochem 2007, 20:887-98.

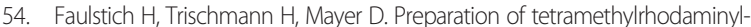
phalloidin and uptake of the toxin into short-term cultured hepatocytes by endocytosis. Exp Cell Res. 1983;144:73-82.

55. Nandi SS, Ghosh P, Roy SS. Expression of PITX2 homeodomain transcription factor during rat gonadal development in a sexually dimorphic manner. Cell Physiol Biochem. 2011;27:159-70. 